\title{
Australian milk fat-Seasonal and regional variation of melting properties
}

\author{
Cornelis Versteeg, ${ }^{*}$ Amy Logan, ${ }^{* 1}$ and Warren Müller† \\ ${ }^{*}$ CSIRO Food and Nutrition, 671 Sneydes Road, Werribee, Victoria, Australia, 3030 \\ †CSIRO Digital Productivity, GPO Box 664, Canberra, ACT, Australia 2601
}

\section{ABSTRACT}

The solid fat content and dropping point of milk fat obtained over $2 \mathrm{yr}$ and from 19 bulk milk production sites across Australia were characterized. Solid fat content at $5^{\circ} \mathrm{C}$ and $20^{\circ} \mathrm{C}$, respectively, ranged between 49.9 and $66.1 \%$ and between 14.6 and $29.6 \%$ across all sites. Dropping point ranged between 30.5 and $35.4^{\circ} \mathrm{C}$. The dropping point did not correlate with solid fat content at lower temperatures across several sites, indicating that it is not an accurate or useful measure of functionality at temperatures of $15^{\circ} \mathrm{C}$ or below. Although at times, considerable variation was observed in milk fat melting properties between sites located in similar geographic regions, statistical analysis by means of boxplots and multidimensional scaling revealed broad similarities within regions over the 24 mo. Multidimensional scaling also revealed similarities between some quite distant and diverse regions (e.g., Queensland and South Australia with constant and seasonal production, respectively). These analyses were used to make 5 groups from the 19 sites to describe seasonal melting properties. The groups with sites in west Victoria, southeast Victoria, and Tasmania showed the largest seasonal variation and range of values, with peaks and lows in southeast Victoria and Tasmania occurring up to 3 mo later than in west Victoria. The group with sites in New South Wales, Queensland, and South Australia had the least variation and range of values, which were relatively high throughout. The group with Western Australian sites showed medium levels of variation but distinct seasonal patterns, with solids fats typically below and dropping points higher than the national average. The Victorian group's lows in dropping point occurred about 2 mo later than did the low values of solid fat content. No single factor stood out as determining the variation in melting properties.

Key words: milk fat, melting properties, solid fat content, dropping point

Received July 20, 2015.

Accepted December 23, 2015.

${ }^{1}$ Corresponding author: amy.logan@csiro.au

\section{INTRODUCTION}

Considerable regional variation occurs from country to country, or regions thereof, in milk composition and functionality with diet, stage of lactation (Kefford et al., 1995), and season (Johnson, 1965; Precht, 1994). This includes the melting properties of milk fat based on the solid fat content (Cox and McDowall, 1948; Norris et al., 1973; Auldist et al., 1998; Walker et al., 2013). Melting properties are an important characteristic of milk fat for processors and consumers alike, as they affect properties such as butter spreadability (Norris et al., 1973), oiling off (Cullinane et al., 1984) and "stand up" (i.e., the relative change in height of a plug of butter) in hot climates (Banks et al., 1983); suitability of milk fat for pastry and other baked products (Deffense, 1993); the whipping properties of cream (Smith et al., 2000); foam stability (Bazmi et al., 2007; Huppertz, 2010); oxidative stability (Hillbrick and Augustin, 2002 ); and the suitability of milk fat for further processing such as blending and fractionation (Deffense, 1993; Shen et al., 2001).

Milk fat has a large melting temperature range of about -40 to $40^{\circ} \mathrm{C}$ (Kankare and Antila, 1988; Lopez et al., 2007) and contains both liquid and solid fat fractions under refrigerated storage conditions. Using differential scanning calorimetry (DSC), Kankare and Antila (1988) noted $84.1 \%$ of milk fat to be in a solid state at $0^{\circ} \mathrm{C}$. This decreased to $64.8 \%$ at $10^{\circ} \mathrm{C}$ and the fat was completely melted at $38^{\circ} \mathrm{C}$. As such, milk fat exhibits melting over a wide temperature range rather than the sharp melting point of pure substances (Deman et al., 1983) or the narrow range exhibited by some other edible fats, such as hardened coconut oil (Kaisersberger, 1989). Measures for melting and solidification points quantify the end and starting points of this range to some level of certainty (McCarthy, 2006). Common methods of analysis for solid fat content (SFC) and the melting properties of a sample as a function of temperature include low-field nuclear magnetic resonance (NMR; Knightbridge and Black, 1978; Auldist et al., 1998), DSC (Kankare and Antila, 1988), near-infrared (NIR) spectroscopy (Meagher et al., 2007), and ultrasound velocity (McClements and 
Povey, 1987). Analysis using NMR and NIR can quantitatively determine the proportion of solid to liquid milk fat at a given temperature, whereas DSC and ultrasound techniques provide information about the melting profile of a sample over a temperature range. All measures, however, can be influenced by tempering or temperature cycling (Boode et al., 1991) and it is essential that samples be completely melted before analysis (usually to $60-70^{\circ} \mathrm{C}$ ) to remove the thermal history, and cooled under standardized conditions. The solid fat content measured by NMR and that derived from DSC measurements can be quite different (Walker and Bosin, 1971), which must be kept in mind when comparing literature values.

A study investigating the thermal properties of milk fat in New Zealand found that the degree of fat in a liquid state was higher in July (mid-winter) compared with October and November (mid- to late-spring), so that SFC increased as the first half of the milking season progressed. The amount of SFC was then observed to decrease into autumn, although not returning to the original July value (Norris et al., 1973). This agrees with Auldist et al. (1998), and as such, maximum hardness in New Zealand butter occurs in mid-summer, whereas the softest butters are made in the spring (Cox and McDowall, 1948; Dolby, 1949; MacGibbon and McLennan, 1987). A study measuring butter firmness and milk fat SFC from factories in the southeast (Gippsland), southwest, and northern regions of Victoria in Australia showed a significant difference in SFC based on region at 5 and $15^{\circ} \mathrm{C}$, but not at $25^{\circ} \mathrm{C}$ (Knightbridge and Black, 1978). This was similar to the observations of Meagher et al. (2007) in New Zealand butter for SFC between 10 and $20^{\circ} \mathrm{C}$. Knightbridge and Black (1978) found higher levels of SFC from samples collected in the southwest region compared with the other Victorian locations between December and March (summer). Moreover, the SFC of milk fat from both southwest and southeast Victoria progressively decreased from March onward but remained constantly high between December and May in samples from the northern region. All regions recorded low SFC levels during the winter period.

Following the work of Knightbridge and Black (1978), a 2-yr Australian-wide survey was conducted in 1994 and 1995. In that study, milk fat properties were determined each month from 19 bulk collection or processing sites in broadly 8 geographic regions spread across Australia. A small part of the data was previously published with limited interpretation (Papalois et al., 1996; Thomas and Rowney, 1996). Considering the richness of the data set, we believe that it is important to further analyze, interpret, and publish the results of this reference work in much more detail. This survey is unique as it covered 2 complete consecutive years and a large number of geographical, climatic, and production system differences within Australia. This work will provide benchmarks for any changes in milk fat properties that may be found in future studies. Furthermore, the confidentiality on the locations of the participating sites has been lifted, allowing a more meaningful interpretation and reporting of the results than was possible at the time of the survey.

In this examination, the geographical, climate, and some farming practices of the surveyed production regions will be detailed. Low-field NMR analysis was used to define the SFC of milk fat extracted from the collected milks and products at $0,5,10,15,20,25,30$, and $35^{\circ} \mathrm{C}$. Further, the milk fat Mettler dropping point (DP) was measured, which determines the temperature at which the first drop of milk fat is detected upon heating from a chilled start-point (Timms, 1978). The fatty acid compositions and triglycerides will be presented, together with any correlations between properties and composition, in subsequent publications.

\section{MATERIALS AND METHODS}

\section{Sample Sites}

Nineteen bulk milk collection sites were surveyed (most of these were also dairy product manufacturing factories). These were located in New South Wales (1 site at the central coast), Queensland (2 sites in the southeast), South Australia (1 site in the southeast), Tasmania (3 sites in the north of the island), Victoria (3 sites in the southwest, 3 sites in the north, and 3 sites in the southeast, or "Gippsland"), and Western Australia (3 sites in the southwest). A single herd research farm in Ellinbank, eastern Victoria, also took part in the survey. Figure 1 shows the geographic location of the participating sites. Seasonal milk production data were made available by several of the participating sites, and weather data and typical farming data were collected where possible. Tables 1 and 2 list the participants and detailed locations of the sites.

\section{Sample Collection and Preparation}

Whole milk, cream, butter, or anhydrous milk fat (AMF) samples were collected at 2 different times of 2 consecutive days in the middle of the month and sent refrigerated overnight to the laboratory. Samples were frozen until further processing within a month. The same type of product sample was collected from each location for the duration of the survey and AMF prepared accordingly with the remaining steps required; 


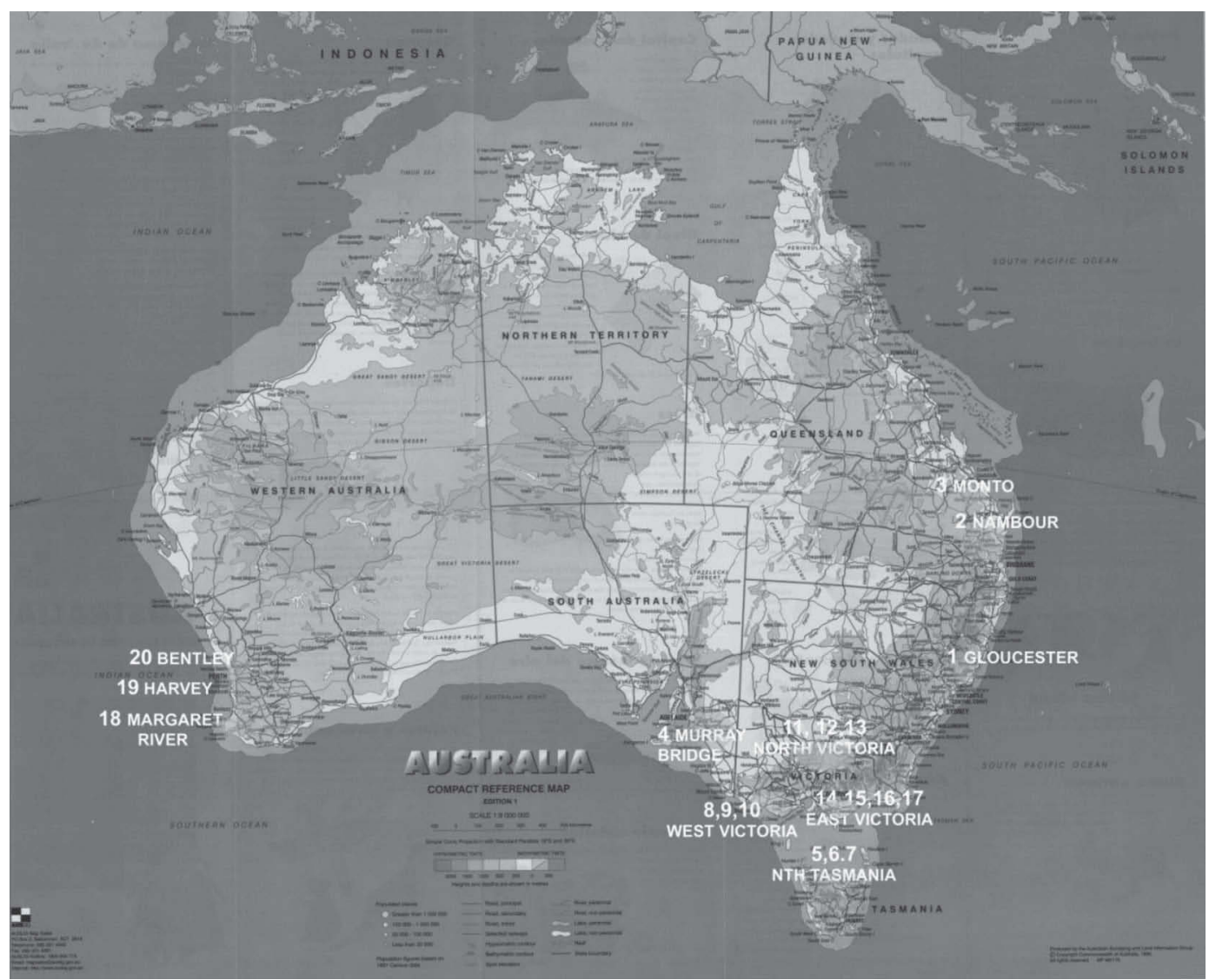

Figure 1. Locations of regions and milk collection sites (1 to 20) for the milk fat survey. (C) Commonwealth of Australia (Geoscience Australia) 2016. This product is released under the Creative Commons Attribution 4.0 International Licence. http://creativecommons.org/licenses/by/4.0/ legalcode.

for example, cream was skimmed by centrifuging for whole milk samples. Refrigerated cream was churned into butter by vigorous shaking in glass flasks. Butter was melted and centrifuged $\left(1,500 \times g, 70^{\circ} \mathrm{C}, 5 \mathrm{~min}\right)$, to separate the AMF and serum into layers. The top AMF layer was collected and the AMF sealed in amber glass ampoules under nitrogen and stored in the dark at $-18^{\circ} \mathrm{C}$ until further analyses. The physical properties of all samples were analyzed within 2 mo after sample receipt.

\section{SFC Analyses}

For SFC measurements, the fats were melted, 1.8 $\mathrm{mL}$ was transferred to NMR tubes $(18 \mathrm{~cm}$ tall, $1 \mathrm{~cm}$ diameter), and held for $45 \mathrm{~min}$ in an oven or for 30 min in a water bath at $60^{\circ} \mathrm{C}$, and then placed in an ice-water bath for $90 \mathrm{~min}$. Using a daily calibrated Minispec PC120 Nuclear Magnetic Resonance instrument (Bruker, Preston, Australia), with standards of $0,31.5$, and $73.0 \%$, SFC were measured starting at $0^{\circ} \mathrm{C}$ and sequentially at 7 further increments of $5^{\circ} \mathrm{C}$ after a 30-min incubation each time in a water bath until the fat was completely melted at $40^{\circ} \mathrm{C}$.

\section{Dropping Point}

The DP was determined as described in Timms (1978) using a Mettler FP83 dropping-point cell with a FP80HT central processor (Mettler Toledo, Port Melbourne, Australia). The milk fat was melted at $70^{\circ} \mathrm{C}$ and aliquots transferred into chilled ME-18732 sample cups (Mettler Toledo) and tempered at $-18^{\circ} \mathrm{C}$ in the freezer for $1 \mathrm{~h}$ before being transferred to the dropping point cell and measurement. From a starting temperature of $25^{\circ} \mathrm{C}$, the sample is held for $30 \mathrm{~s}$ before a heating rate at $1^{\circ} \mathrm{C} / \mathrm{min}$ is applied. The temperature at which the milk fat becomes liquid and drops past a sensor is recorded by the instrument.

\section{Statistical Methods}

All statistical analyses were conducted using GenStat (GenStat, 2013). Box plots were prepared for the 8 SFC 
VERSTEEG ET AL.

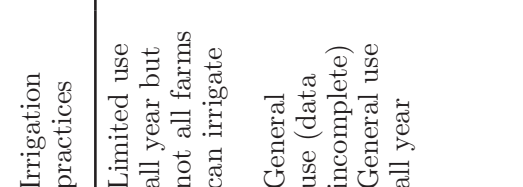

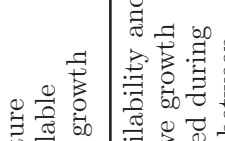

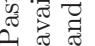

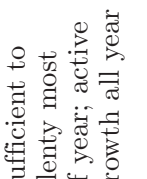

م.

है

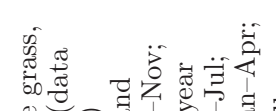

要

荡

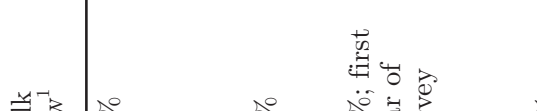

禁

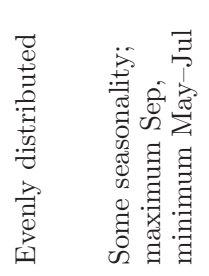

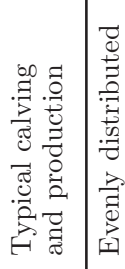

(2)

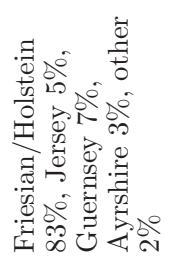

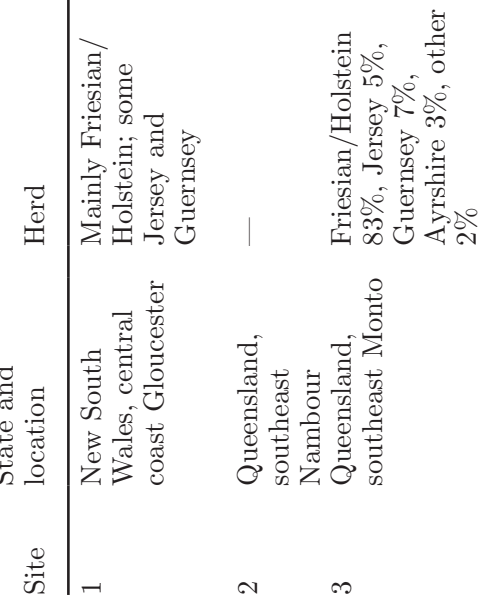

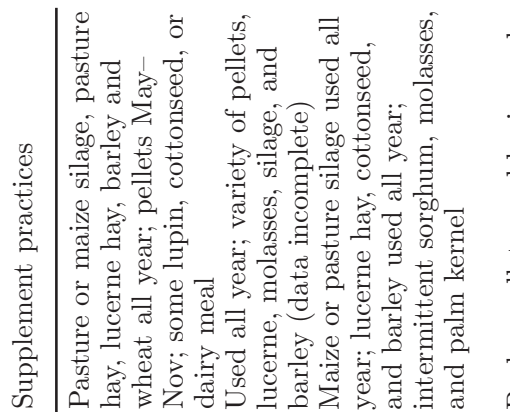

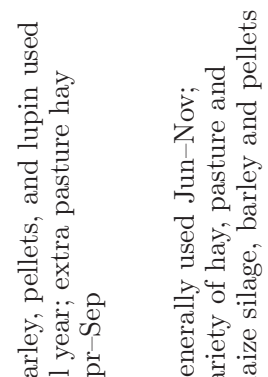

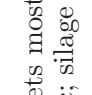

总苍范

苛总空

若

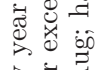

ङ

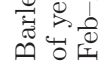

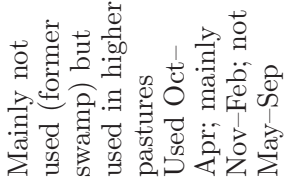

焉

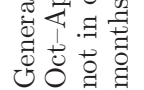

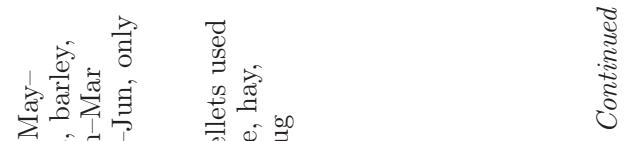

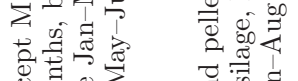

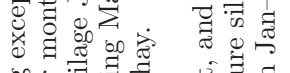

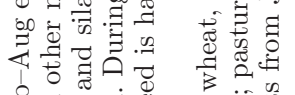

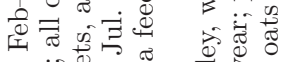

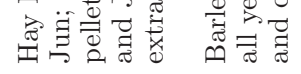

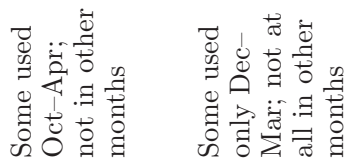

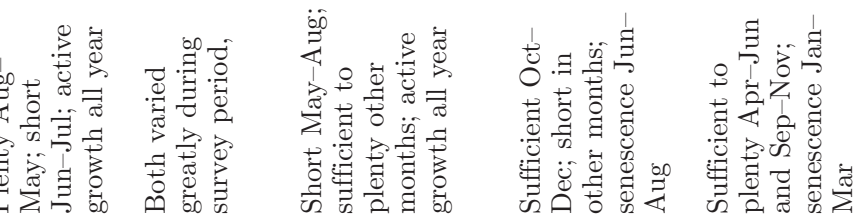

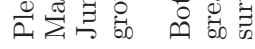

क ⿻ ㇒ थ 20

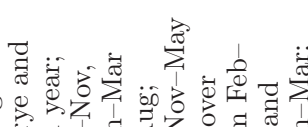

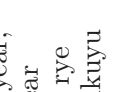

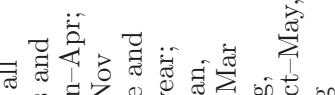

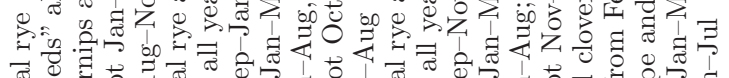

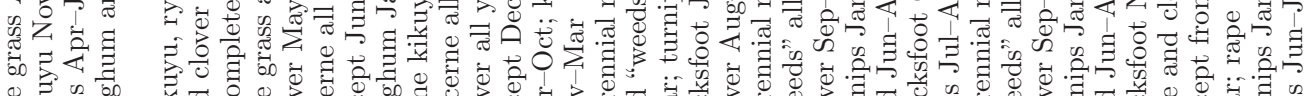

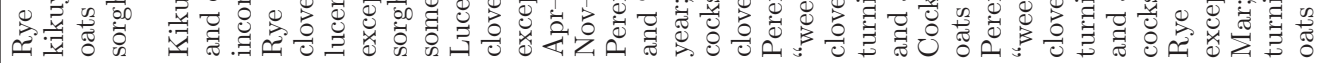

市

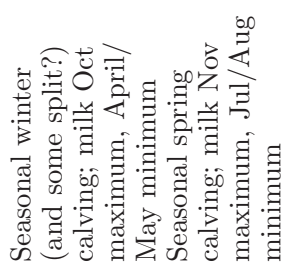

$\stackrel{0}{\circ}$

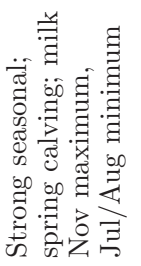

合 站

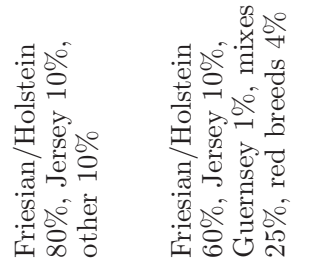

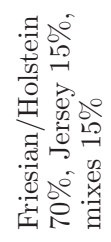

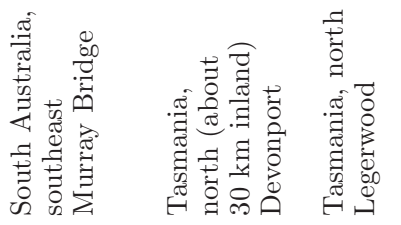

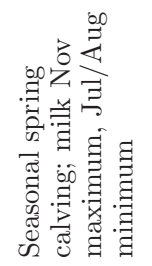

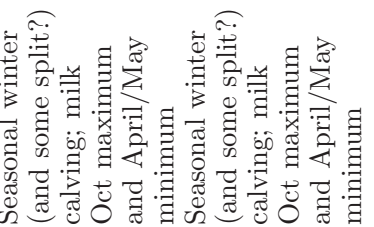

Journal of Dairy Science Vol. 99 No. 4, 2016 


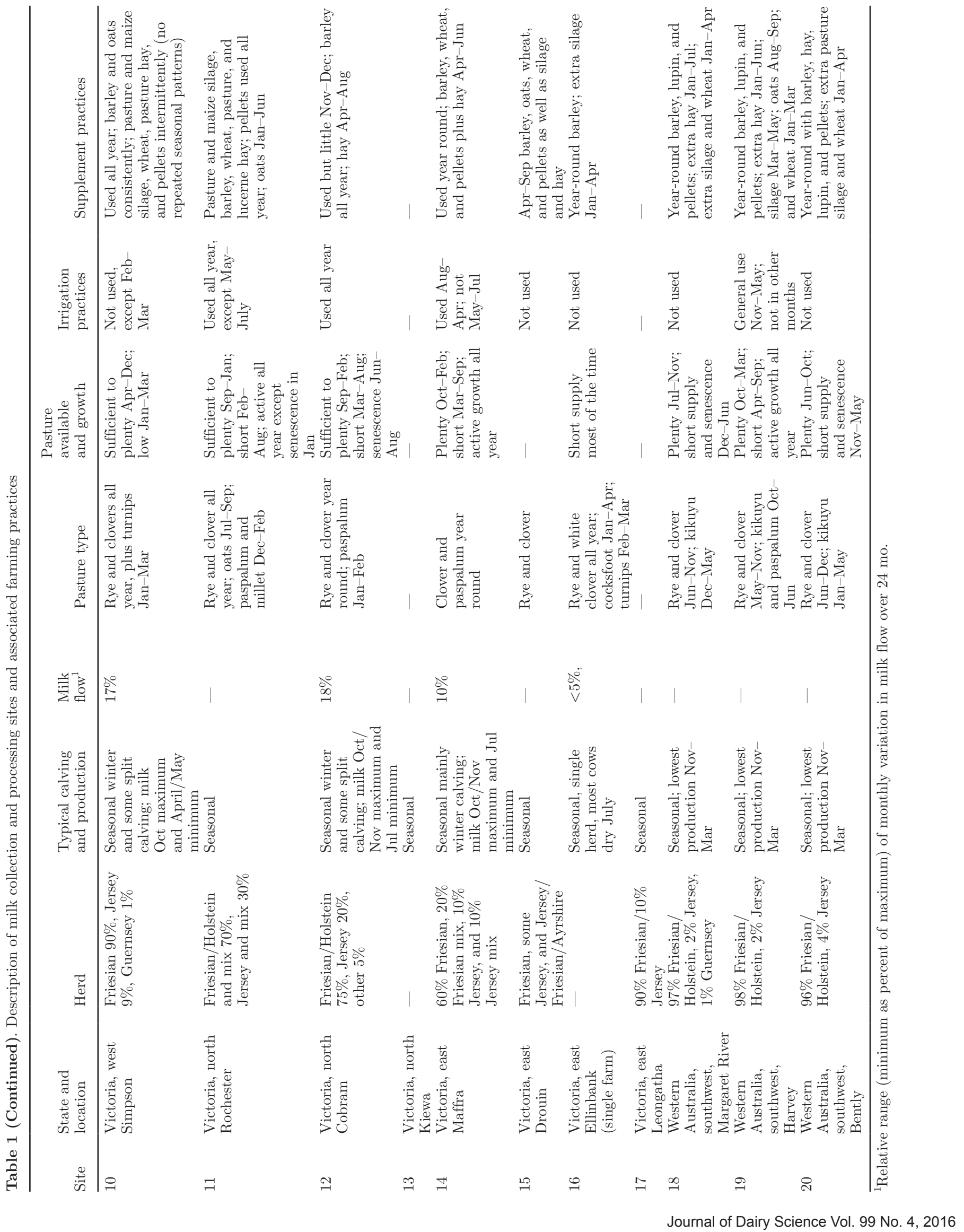


measurements and DP to represent the variability of each measurement over the $24 \mathrm{mo}$, and relationships between the measurements were examined by calculating all pair-wise correlations and testing their significances (Fisher and Yates, 1963). Samples were unavailable from some sites for some months $(12.1 \%$ of all site $\times$ year $\times$ month combinations) so a nonorthogonal linear mixed model (LMM) analysis was performed on data available for each site using REML (Patterson and Thompson, 1971; Robinson, 1987). From the LMM analyses, an estimate for each site of variability within months was obtained. As the 2 to 4 replicate samples were taken sequentially at different times on the same or next day in the middle of the month, these estimates represented the sampling variation of the solid fat measurements. Bartlett's tests of homogeneity of variation (Bartlett, 1937) were performed for each variable across the 20 sites to determine whether all measurements could be combined into a single statistical analysis.

The single herd research farm in Ellinbank, east Victoria, was excluded from further analyses because of its atypical characteristics and responses. To determine similarity between the remaining 19 sites in SFC and DP over the $2 \mathrm{yr}$, multidimensional scaling (Cox and Cox, 2010) was done on the variables. The similarity matrix was calculated in each case using the "city block" metric (Digby and Kempton, 1987; Gordon, 1999), which for each pair of sites calculates the absolute difference between their values for the 24 mo and calculates the mean of these differences. This metric was preferred as it does not give undue weight to outlying values, and months with missing values are ignored, providing a good estimate of the "distances" between responses over 24 mo. Metric and nonmetric multidimensional scaling were performed at both 2 and 3 dimensions. Examination of stress calculated from the scaling showed that nonmetric scaling in 3 dimensions performed best, with lower stress values than the other combinations for most variables, and it was used to examine groupings of the 19 sites.

\section{RESULTS AND DISCUSSION}

As it was not feasible to report the details of seasonal variation of melting properties at all temperatures, we focused on 3 melting properties for presentation and discussion. This was supported by the high correlation between most melting properties at most sites. Selected were $\mathrm{SFC}(\%)$ at $5^{\circ} \mathrm{C}$, representing properties at refrigerator temperatures; SFC (\%) at $20^{\circ} \mathrm{C}$, representing properties at ambient temperatures; and DP $\left({ }^{\circ} \mathrm{C}\right)$, representing the melting temperature of the milk fats. The complete dataset for all SFC results across all temperatures is provided as supplementary data to support

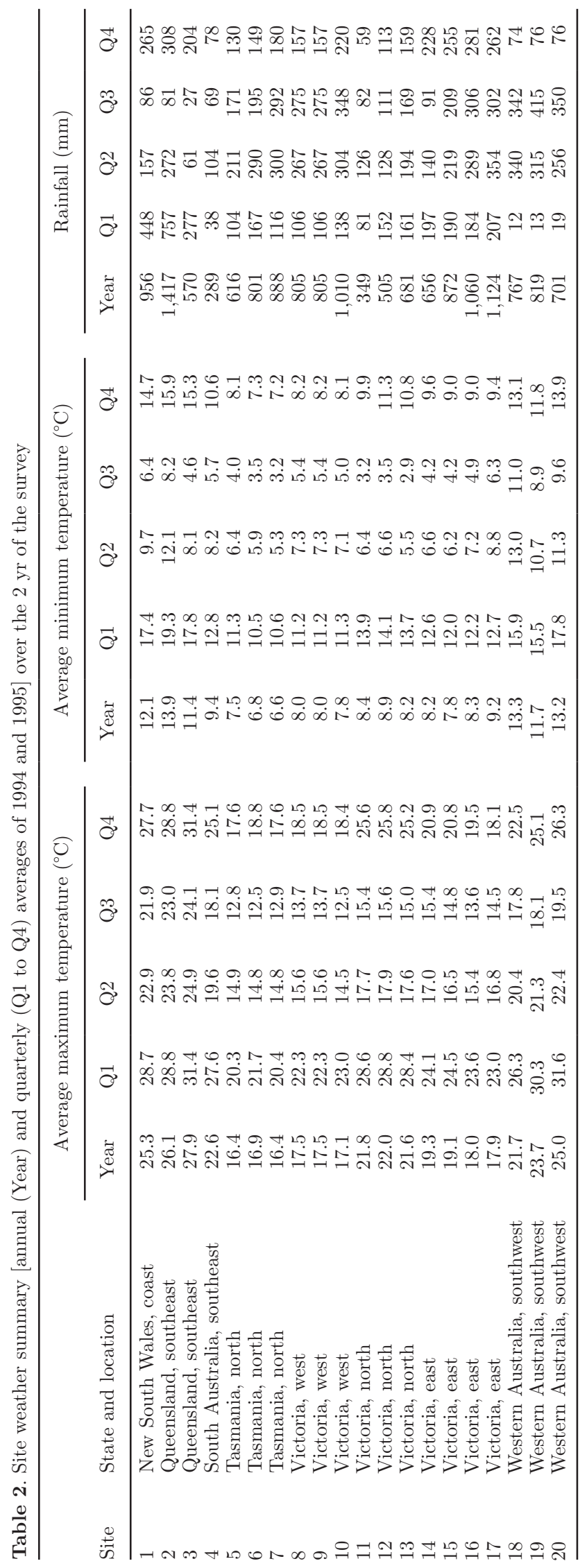


the findings in this paper and for further examination if desired (http://dx.doi.org/10.3168/jds.2015-10146).

\section{Characterization of Participating Sites}

The locations of participating sites are indicated in Figure 1, and further details and associated farming, milk production, and climate data are summarized in Tables 1 and 2. The quarters in Table 2 approximate the official Australian seasons, which start 1 mo earlier; for example, summer is from December 1 to February 28. Sites range from the subtropics in Queensland to cold climates in Tasmania.

\section{Rainfall}

Annual rainfall varied from less than $400 \mathrm{~mm} / \mathrm{yr}$ in South Australia and 1 site in northern Victoria to more than $1,000 \mathrm{~mm} / \mathrm{yr}$ in 1 of the Queensland sites and some of the Victorian sites. In New South Wales and Queensland, the highest rainfalls were in the first and last quarters of the year, whereas in Western Australia, there was virtually no rainfall in the first quarter, and most rain (more than 85\%) fell in the second and third quarters. All other sites had more evenly distributed rainfall in all quarters.

\section{Temperatures}

Daily minimum temperatures in the third quarter ( winter) averaged about $3^{\circ} \mathrm{C}$ in northern Victoria and Tasmania to about 8 to $11^{\circ} \mathrm{C}$ in parts of Queensland and Western Australia. Daily average maximum temperatures were highest in the first quarter $(\sim$ summer $)$ for all sites, except for the sites in New South Wales and Queensland, in which temperatures were about equal to those in the fourth quarter $(\sim$ spring $)$. The first-quarter average maximum temperatures varied from about $20^{\circ} \mathrm{C}$ in Tasmania to over $28^{\circ} \mathrm{C}$ in New South Wales, Queensland, northern Victoria, and 1 site in Western Australia.

\section{Breeds}

It is important to note that many sites collected milk from large areas, which could be more than $200 \mathrm{~km}$ away from the collection point, sometimes overlapping with the intake areas of other sites involved in this study. Friesian/Holstein breeds dominated in all districts, accounting, on average, for 60 to $90 \%$ of all animals, with the exception of site 7 in Tasmania, which had 88\% "mixed breeds," and in Western Australia, where the Friesian/Holstein breed contributed to about $96 \%$ or more of all animals. Pure Jersey ( $10 \%$ or more of the herd) were found in South Australia, 2 of the sites in Tasmania, and 1 site in Northern Victoria. There were very small proportions of other breeds such as Guernsey, Ayrshire, and "red breeds" in some districts.

\section{Seasonality of Milk Production}

The New South Wales and Queensland sites had relatively stable year-round production systems with split and continuous calving, resulting in a continuous milk supply. The South Australia site and all Victorian and Tasmanian sites had strong seasonal production and associated seasonal calving patterns, with peak production in spring and early summer. All Western Australia sites also had seasonal production with milk volume peaks in winter and early spring and low production from November to March (the opposite production seasons of South Australia, Victoria, and Tasmania). Typically, cows were not housed across the season in any of the regions.

\section{Pasture}

Pasture types varied strongly by region and season. In several of the warmer regions, Kikuyu grass was an important feed for 4 to 6 mo between November and May of each year, as was reported for sites in New South Wales, Queensland, South Australia, and Western Australia. In most areas, rye grass and clover contributed significantly to the pasture feed for at least part, and often all, of the year. In South Australia and Victoria, clover was available virtually all year, whereas in Queensland, Tasmania, and Western Australia, clover was mainly available in winter and spring. Rye grass was available almost all year in Tasmania, in all districts in Victoria, and seasonally in New South Wales, Queensland, South Australia, and Western Australia, typically from late autumn (April/May) to the end of spring (November/December). One site in Queensland and the South Australia site stood out with year-round availability of lucerne pastures. Pasture availability varied greatly by region, typically being short from mid-summer to mid-winter in Tasmania and in most northern and eastern Victorian sites.

As may be expected from the rainfall patterns, Western Australia generally had the best pasture supplies in winter and spring but were short in summer and autumn. Pasture availability in western Victoria was low in summer (December to March) but generally good in the other seasons. 
Table 3. Within-month variance and $\mathrm{CV}$ for solid fat content (SFC; \%) at $5^{\circ} \mathrm{C}$ and $20^{\circ} \mathrm{C}$ and dropping point $\left({ }^{\circ} \mathrm{C}\right)$ for the 20 sites

\begin{tabular}{|c|c|c|c|c|c|c|}
\hline \multirow[b]{2}{*}{ Site } & \multicolumn{2}{|c|}{$\mathrm{SFC}$ at $5^{\circ} \mathrm{C}$} & \multicolumn{2}{|c|}{$\mathrm{SFC}$ at $20^{\circ} \mathrm{C}$} & \multicolumn{2}{|c|}{ Dropping point } \\
\hline & Variance & $\mathrm{CV}(\%)$ & Variance & $\mathrm{CV}(\%)$ & Variance & $\mathrm{CV}(\%)$ \\
\hline 1 & 0.463 & 1.16 & 0.274 & 2.60 & 0.053 & 0.70 \\
\hline 2 & 0.199 & 0.77 & 0.128 & 1.81 & 0.068 & 0.78 \\
\hline 3 & 0.509 & 1.23 & 0.488 & 3.45 & 0.137 & 1.09 \\
\hline 4 & 0.499 & 1.21 & 0.373 & 3.05 & 0.075 & 0.83 \\
\hline 5 & 0.126 & 0.60 & 0.074 & 1.36 & 0.038 & 0.59 \\
\hline 6 & 0.872 & 1.62 & 0.097 & 1.65 & 0.057 & 0.73 \\
\hline 7 & 0.630 & 1.34 & 0.165 & 2.02 & 0.063 & 0.76 \\
\hline 8 & 0.442 & 1.14 & 0.413 & 3.12 & 0.102 & 0.97 \\
\hline 9 & 0.285 & 0.90 & 0.287 & 2.55 & 0.060 & 0.73 \\
\hline 10 & 0.538 & 1.28 & 0.348 & 3.05 & 0.073 & 0.82 \\
\hline 11 & 0.772 & 1.47 & 0.916 & 4.60 & 0.178 & 1.28 \\
\hline 12 & 0.292 & 0.91 & 0.433 & 3.15 & 0.119 & 1.04 \\
\hline 13 & 0.490 & 1.20 & 0.236 & 2.39 & 0.074 & 0.82 \\
\hline 14 & 0.376 & 1.08 & 0.334 & 3.13 & 0.122 & 1.08 \\
\hline 15 & 1.575 & 2.18 & 1.262 & 5.74 & 0.169 & 1.24 \\
\hline 16 & 4.083 & 3.28 & 3.433 & 7.60 & 0.153 & 1.16 \\
\hline 17 & 0.306 & 0.97 & 0.156 & 2.03 & 0.033 & 0.55 \\
\hline 18 & 0.404 & 1.13 & 0.213 & 2.46 & 0.074 & 0.82 \\
\hline 19 & 0.210 & 0.80 & 0.247 & 2.53 & 0.093 & 0.91 \\
\hline 20 & 0.987 & 1.80 & 0.450 & 3.51 & 0.169 & 1.21 \\
\hline
\end{tabular}

\section{Irrigation}

Irrigation was used virtually all year by most farms in New South Wales, Queensland, and northern Victoria, more seasonally in summer in Tasmania and western Victoria, and in winter in 1 district in Western Australia. Typically, no irrigation was used in regions of South Australia and the other 2 sites in Western Australia

\section{Supplements}

Supplementary feeds were used in all districts; the most consistent year-round supplements were used in New South Wales, Queensland, South Australia, and Western Australia. Barley and pellets featured as a supplementary feed in nearly all districts, for at least some part of the year. Other than that, there was a great variety in supplementary feeds, depending on the district or season, with oats, wheat, pasture, and maize silage, and pasture and lucerne hay featuring prominently. Cottonseed, sorghum, molasses, and palm kernels were used in only a few regions, and lupin was commonly used in Western Australia.

\section{Farming Practices}

From this overview, it is clear that a large diversity of farming practices and climates were represented in the survey. Significant climatic and farming practice differences may also occur in sites relatively close to each other; for example, rainfall in Queensland (sites 2 and 3) and northern Victoria (sites 11 and 13). Farming practices have changed since 1995, particularly in South Australia and Victoria, with less seasonal milk production occurring. In the 2014-2015 season, the average low (relative to peak) milk production volume for South Australia was about $75 \%$ and for all regions combined in Victoria, it was about 55\% (Dairy Industry in Focus, 2015) compared with $<20 \%$ for both at the time of the survey (Table 1). This increase in off-peak production was achieved by changed calving patterns from seasonal to split and extended calving and often, but not always, by more intensive feeding systems that rely less on pasture (Hauser and Lane, 2013). Tasmania still had a strong seasonal milk production with a low of about $25 \%$ of the peak (Dairy Industry in Focus, 2015).

\section{Variability Between Duplicates}

Variability between duplicate measurements (from 2 to 4 separate samples taken sequentially at different times on same or next day) within months was estimated from the separate LMM analyses performed for measurements at each site. Within-month variances for SFC at $5^{\circ} \mathrm{C}$ and $20^{\circ} \mathrm{C}$ and DP are presented in Table 3 . We found substantial differences in within-month variance between sites for SFC at all temperatures and for DP, with all Bartlett's tests being highly significant ( $P$ $<0.001)$. Site 16 showed much higher variability than the other sites from $0^{\circ} \mathrm{C}$ to $30^{\circ} \mathrm{C}$, and was at the high end of the variances for DP. Some other sites showed 
consistently higher variability (e.g., 11 and 15) or lower variability (e.g., 2 and 5 ), whereas relative variability in some sites changed as temperature increased (e.g., 3 and 6). This wide range of variability across sites meant that a single statistical analysis for each variable across all sites could not be performed due to violation of the assumption of homogeneity of variation. Therefore, comparisons between sites or across time within sites were made using standard errors derived from the separate LMM analyses for each site. Within-month coefficients of variation (CV) for DP and for SFC up to $15^{\circ} \mathrm{C}$ were typically around $1 \%$ and well below $5 \%$ for all sites (results for $5^{\circ} \mathrm{C}$ and DP in Table 3). For SFC at 20,25 , and $30^{\circ} \mathrm{C}$, the $\mathrm{CV}$ were below $10 \%$ for all sites; however, those for $35^{\circ} \mathrm{C}$ were much higher and ranged

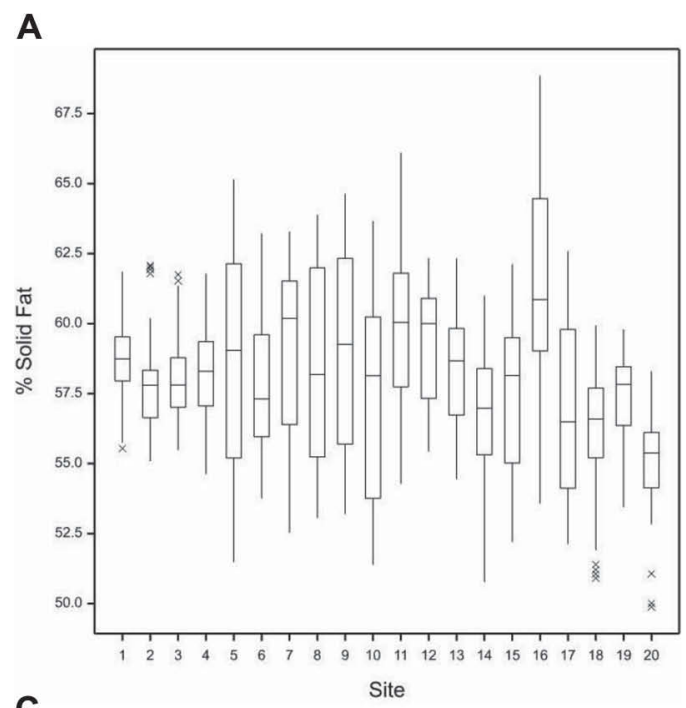

C

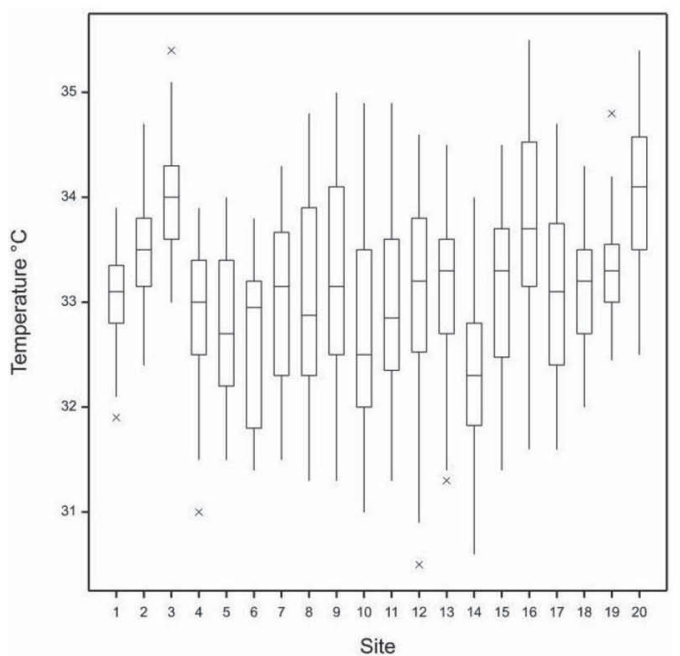

between 22 and $67 \%$ due to the very low SFC (0-2.4\%), at that temperature (results for $20^{\circ} \mathrm{C}$ in Table 3, other results not shown). Hence, determination of SFC at $35^{\circ} \mathrm{C}$ could be regarded as unreliable. We detected no apparent association between levels of variability and regions from which milk samples were obtained (Tables 1 and 3). For example, Queensland sites 2 and 3 showed substantial differences in variability.

\section{Melting Properties}

The previous report by Papalois et al. (1996) examined these samples based on just 2 groupings; all of Australia (i.e., all sites combined) and Victoria (i.e., sites 8-17 combined). They found that both SFC and DP

B

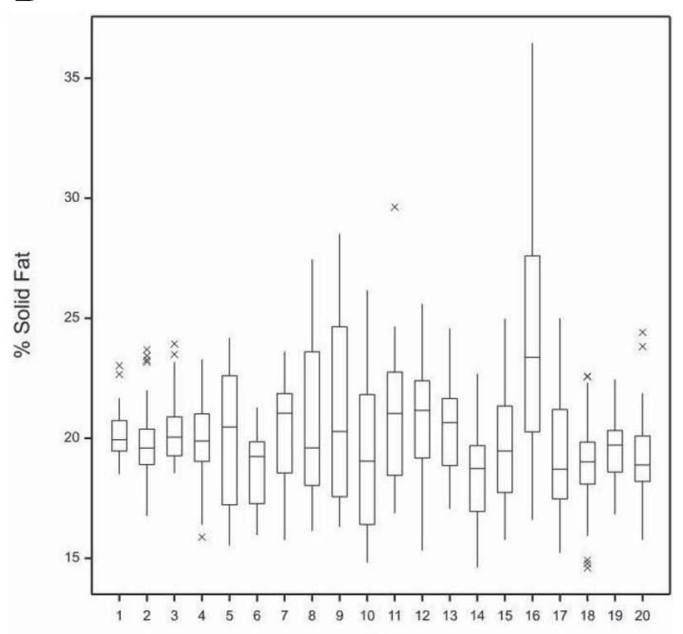

Site
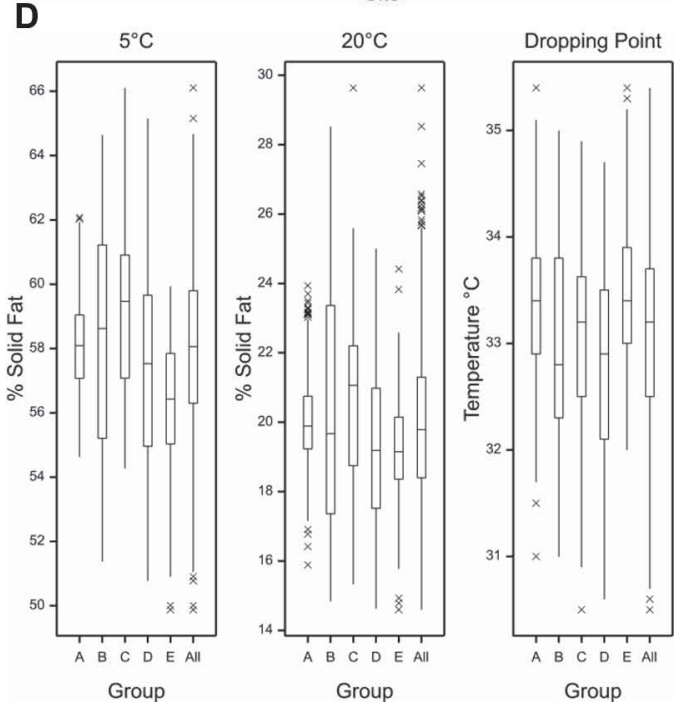

Figure 2. Box plots of (A) solid fat at $5^{\circ} \mathrm{C}$, (B) solid fat at $20^{\circ} \mathrm{C},(\mathrm{C})$ dropping point $\left({ }^{\circ} \mathrm{C}\right)$ of all samples from each site, with median, interquartile range, which contains $50 \%$ of the values, whiskers covering values up to $1.5 \times$ interquartile range, and outliers $(\times)$; and $(\mathrm{D})$ solid fat at $5^{\circ} \mathrm{C}$ and $20^{\circ} \mathrm{C}$, and dropping point, for all samples from sites grouped into 5 regions (A to E), and from all sites except site 16 (All). 


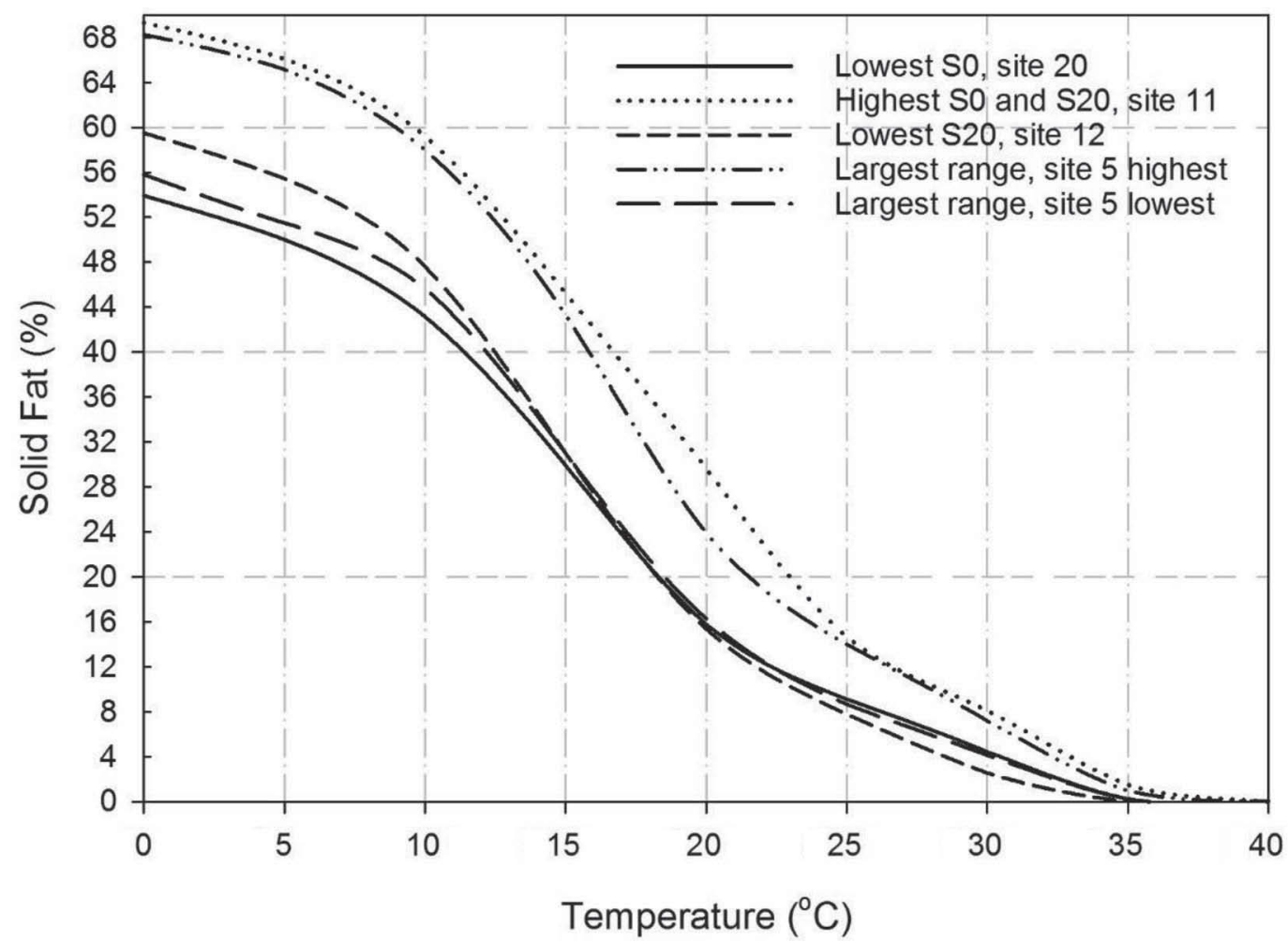

Figure 3. Melting curves of individual samples selected to represent the range of solid fat content (SFC) values. Site numbers for the samples are given in the caption. Lowest $\mathrm{S} 0=$ sample with lowest $\mathrm{SFC}$ at $0^{\circ} \mathrm{C}$; highest $\mathrm{S} 0$ and $\mathrm{S} 20=$ sample with highest $\mathrm{SFC}$ at both $0^{\circ} \mathrm{C}$ and $20^{\circ} \mathrm{C}$; lowest $\mathrm{S} 20=$ sample with lowest $\mathrm{SFC}$ at $20^{\circ} \mathrm{C}$; largest range $=$ highest and lowest samples from the site with the largest $\mathrm{SFC}$ range at $0^{\circ} \mathrm{C}$.

were similar across geographical region combinations, with milk fat being hardest in the summer months and softest across the winter. Similarly, peaks in DP were observed in the summer to autumn months, whereas troughs were recorded between winter and spring. Box plots for the current analysis of $\mathrm{SFC}$ at $5^{\circ} \mathrm{C}, \mathrm{SFC}$ at $20^{\circ} \mathrm{C}$, and DP of all individual sites are shown in Figure $2 \mathrm{~A}, \mathrm{~B}$, and $\mathrm{C}$, respectively.

\section{SFC}

Although our range of SFC values is wider than reported in the cited studies, the SFC values reported herein were broadly consistent with those of Meagher et al. (2007) for New Zealand milk fat at $5^{\circ} \mathrm{C}$ and $20^{\circ} \mathrm{C}$, and similar to those of Knightbridge and Black (1978) in the SFC of Victorian milk fat measured at $5^{\circ} \mathrm{C}$. Similarities between some sites can be observed. Sites 1 to 4, which encompass sites in New South Wales, Queensland, and South Australia, had SFC over a narrow interquartile range at both temperatures and several outliers on the high side, ranging from about 55 to $62.5 \%$ solid fat at $5^{\circ} \mathrm{C}$ and $16^{\circ} \mathrm{C}$ to $24 \%$ solid fat at $20^{\circ} \mathrm{C}$. Sites 18 to 20 in Western Australia also had narrow interquartile ranges, but with outliers mainly on the low side, and values ranging from about 50 to $60 \%$ solid fat at $5^{\circ} \mathrm{C}$, and from 15 to $24 \%$ at $20^{\circ} \mathrm{C}$. All other sites had much wider interquartile and extreme value ranges, with virtually no outliers. Site 16 in eastern Victoria, the single-herd research farm in Ellinbank, stood out, with a wide range in SFC and the highest median values at both temperatures (60.8 and $23.2 \%$, respectively). Although beyond the scope and purpose of this survey, the exceptional results of this 200-head herd in eastern Victoria show that any desirable milk fat melting properties could be supplied in bulk to manufacturers if the right incentives were given to the relevant farms in the region.

Of the bulk milk collection sites, the highest SFC values at $5^{\circ} \mathrm{C}$ were $66.1 \%$ for site 11 in northern Victoria and $65.2 \%$ for site 5 in Tasmania. The site with the lowest median $\mathrm{SFC}$ at $5^{\circ} \mathrm{C}$ was site 20 in Western Australia (55.4\%), which also had the lowest measured value of the survey at $5^{\circ} \mathrm{C}$ of $49.9 \% \mathrm{SFC}$. Site 11 also had the sample with the highest SFC at $20^{\circ} \mathrm{C}$ of $29.6 \%$, followed by site 9 in western Victoria with $28.5 \%$ SFC. The lowest value was found at site 14, in eastern Victoria, with $14.6 \%$. The lowest median values at $20^{\circ} \mathrm{C}$ were recorded on eastern Victorian sites on sites 14 and 17 . Stage of lactation and seasonal variation have also been 
shown to influence $\mathrm{SFC}$ at $10^{\circ} \mathrm{C}$ in cows throughout a year (Auldist et al., 1998). Although stages of lactations were not captured directly in this survey, milk production data provide a strong indicator of calving patterns. Sites 1 and 2 had very stable milk production systems and site 4 had very strong seasonal production. Nevertheless, the range and median SFC of these 3 sites were very similar.

To better indicate the wide range of different melting curves at the bulk milk sites, a selection of SFC at all measuring temperatures is presented in Figure 3. Shown are samples from July 1994 at site 20 (Western Australia), which had the lowest measured SFC of any sample at $0^{\circ} \mathrm{C}$; September 1995 of site 12 (northern Victoria), which had the lowest SFC of any site at $20^{\circ} \mathrm{C}$; March 1995 of site 11 (northern Victoria), which had

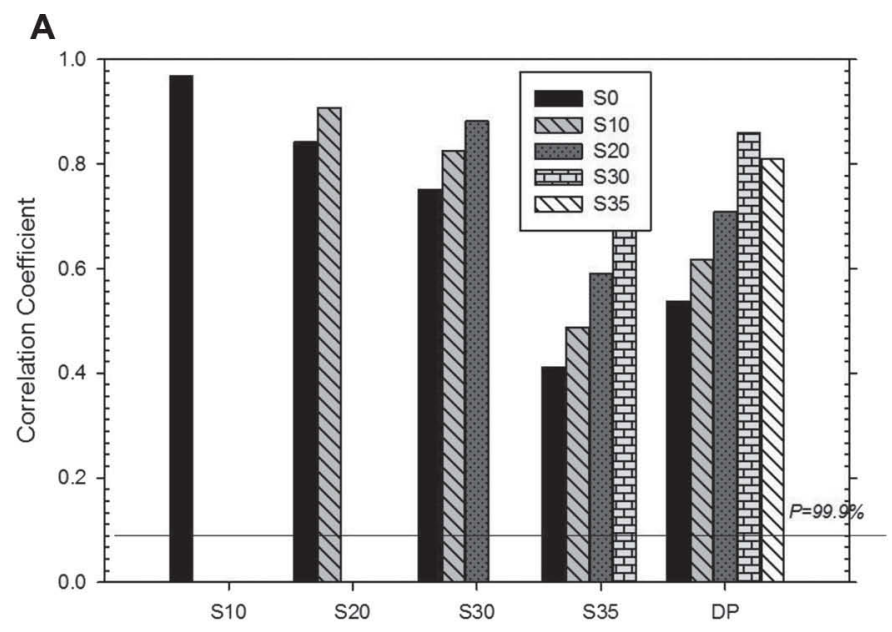

Solid fat at indicated temperature and dropping point (DP)

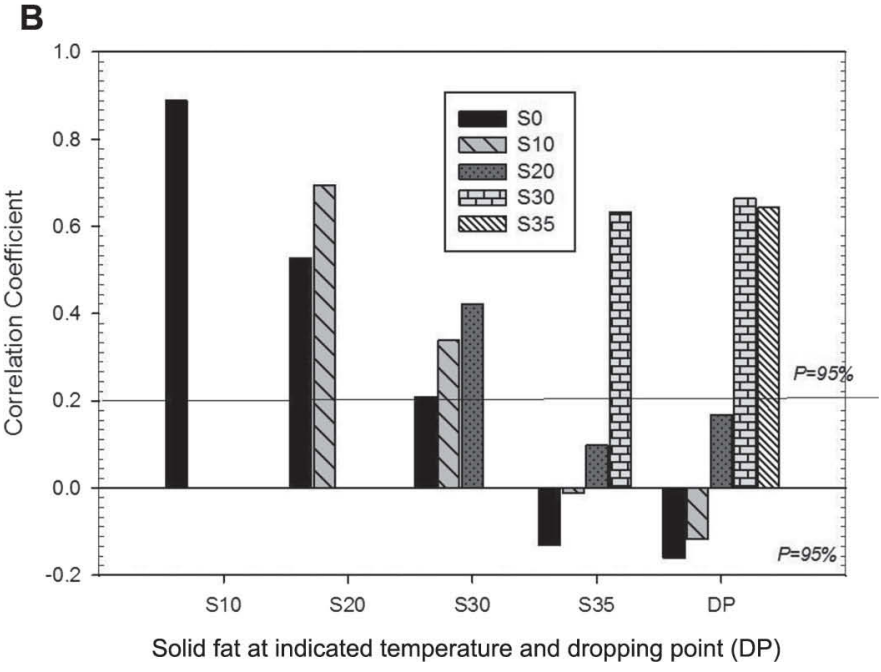

Figure 4. Correlations between solid fat content $(\mathrm{SFC})$ at $0^{\circ} \mathrm{C}(\mathrm{S} 0)$, $10^{\circ} \mathrm{C}(\mathrm{S} 10), 20^{\circ} \mathrm{C}(\mathrm{S} 20), 30^{\circ} \mathrm{C}(\mathrm{S} 30), 35^{\circ} \mathrm{C}(\mathrm{S} 35)$, and dropping point (DP) for all samples (A) from all sites over $2 \mathrm{yr}(\mathrm{n}=1,397)$ and $(\mathrm{B})$ from site 1 over 2 yr $(\mathrm{N}=94)$.

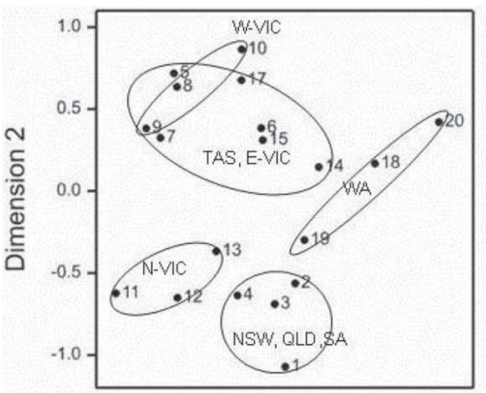

Groupings and sites

A 1: New South Wales (NSW)

2,3: Queensland (OLD)

4: South Australia (SA)

B $8,9,10$ : Western Victoria (W-VIC)

C 11,12,13: Northern Victoria (N-VIC)

D $5,6,7$ : Tasmania (TAS)

14,15,17: Eastern Victoria (E-Vic)

E 18,19,20: Western Australia (WA)
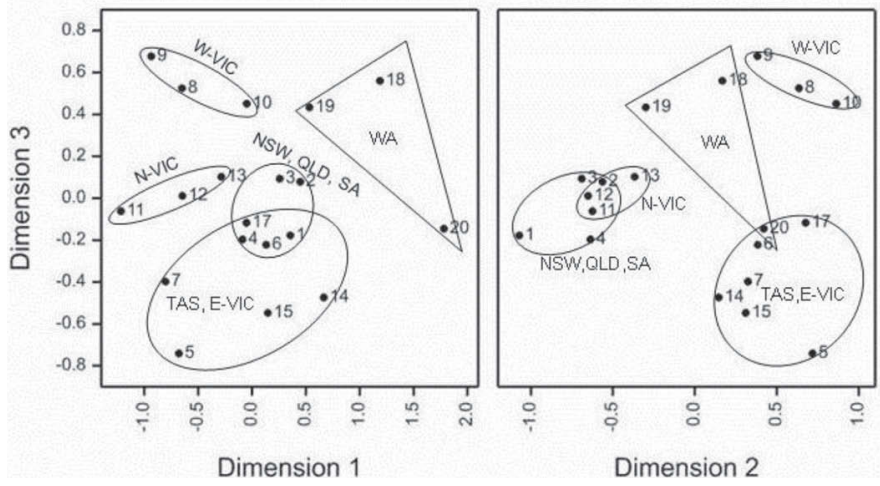

Figure 5. Nonlinear multidimensional scaling of solid fat at $5^{\circ} \mathrm{C}$, with site numbers and selected groupings (A to E) of similar sites in all 3 dimensions.

the highest $\mathrm{SFC}$ at both $0^{\circ} \mathrm{C}$ and $20^{\circ} \mathrm{C}$ and 2 curves of site 5 (Tasmania), which had the widest range of SFC at $0^{\circ} \mathrm{C}$ of any bulk milk site; December 1994 with the highest curve; and August 1995 with the lowest curve for that site. The melting curves of some sites cross over: the SFC of site 12 are higher than those of sites 5 and 20 at $15^{\circ} \mathrm{C}$ and below that temperature but lower at $20^{\circ} \mathrm{C}$ and above.

\section{$D P$}

Dropping point values were in range of that in the literature for milk fat produced in Australia (Timms, 1978) and elsewhere (Deman et al., 1983). Similarities between sites were less clear for DP than for SFC. The highest readings were for site 3 in Queensland and site 20 in Western Australia of $35.4^{\circ} \mathrm{C}$, which also had the highest median values of 34 and $34.1^{\circ} \mathrm{C}$, respectively. Similarities between sites 1 to 4 and sites 18 to 20 are not as obvious as they were for the SFC at 5 and $20^{\circ} \mathrm{C}$; however, as groups, these sites exhibited relatively high DP compared with most other sites. In contrast, sites 1 to 4 were about average and sites 18 to 20 were lower in $\mathrm{SFC}$ at 5 and $20^{\circ} \mathrm{C}$ than most other sites. The lowest DP were observed for sites 12 in northern Victoria $\left(30.5^{\circ} \mathrm{C}\right)$ and 14 in eastern Victoria $\left(30.6^{\circ} \mathrm{C}\right)$. Site 14 also had the lowest median DP of $32.5^{\circ} \mathrm{C}$. Timms (1978) found that the dropping point method as used in our survey 
gives similar results to the softening point, as measured by the ball-and-tube method (Barnicoat, 1944). The range and values of softening points measured by Cox and McDowall (1948) from 9 locations over $4 \mathrm{yr}$ in New Zealand $\left(30.6\right.$ to $\left.34.6^{\circ} \mathrm{C}\right)$ were close to our results. Precht (1994) determined the DP from milk fat collected weekly from 4 German regions over a period of a year. The values (of about 200 samples) ranged from a low of $29.7^{\circ} \mathrm{C}$ and a high of $33.9^{\circ} \mathrm{C}$, which, although about $1^{\circ} \mathrm{C}$ lower, reflect the range and values presented in the current work. This range was broadly discussed by Papalois et al. (1996), who reported a range across sites of 2.5 to $3.5^{\circ} \mathrm{C}$ in summer and $4^{\circ} \mathrm{C}$ in winter. Further, in an earlier Australian study, Parodi (1979) observed a range in softening point between 31.2 and $34.1^{\circ} \mathrm{C}$ over a 12-mo period (the study involving 37 samples from 2 Queensland sites, different from those reported herein).

\section{Correlations}

Correlations between melting properties (SFC between $0^{\circ} \mathrm{C}$ and $35^{\circ} \mathrm{C}$ at $5^{\circ} \mathrm{C}$ intervals and $\mathrm{DP}$ ) were calculated for all sites combined and for each site individually. For all sites combined, the melting properties were all positively correlated and highly significant $(P<0.001)$, although the correlation coefficients for SFC decreased at greater temperature differences (Figure 4A). For example, the correlation coefficient between $\mathrm{SFC}$ at $0^{\circ} \mathrm{C}(\mathrm{S} 0)$ and $10^{\circ} \mathrm{C}(\mathrm{S} 10)$ was 0.969 and that between $0^{\circ} \mathrm{C}$ and $35^{\circ} \mathrm{C}(\mathrm{S} 35)$ was 0.412 . Note that with the approximately 1,400 observations, a correlation coefficient of 0.07 is sufficient for significance at the 99\% level (Fisher and Yates, 1963). For some individual sites, the correlations were less pronounced; nevertheless, correlations between $\mathrm{SFC}$ at $0^{\circ} \mathrm{C}$ and $35^{\circ} \mathrm{C}$ were still significant at the $99 \%$ level for all individual sites except for sites 1 and 19. To characterize melting properties at higher temperatures, the DP, as shown in the "Variability Between Duplicates" section, is a much more accurate analysis than $\mathrm{SFC}$ at $35^{\circ} \mathrm{C}$ and is typically between $30^{\circ} \mathrm{C}$ and $35^{\circ} \mathrm{C}$. Although from different geographic regions, sites 5, 9, 11, and 16, with correlation coefficients of $>0.8$, showed the strongest positive correlations between $\mathrm{DP}$ and $\mathrm{SFC}$ at $0^{\circ} \mathrm{C}$. For sites 1 and 19, the correlation coefficient between DP and SFC at the low temperatures decreased rapidly to become insignificant and became negative for site 1 (Figure 4B).

Monthly replicates of the melting data for sites 1 and 19 were similar, with $\mathrm{CV}$ of $1 \%$ or less for $\mathrm{SFC}$ at $5^{\circ} \mathrm{C}$ and DP. This confirms that for these 2 sites, SFC at low and high temperatures were independent of each other. Thus, for these sites, from an analytical and operational perspective, the relatively easy to perform DP analyses provide no information about the likely SFC and functionality at low temperatures, which would need to be separately determined. Norris et al. (1973) showed a positive correlation between milk fat softening and the temperature at which $94 \%$ of fat was in the liquid state. However, they observed no correlation between softening point and the amount of liquid fat at any temperatures between -20 and $30^{\circ} \mathrm{C}$, except for a weak negative correlation at $22^{\circ} \mathrm{C}$ (with a correlation coefficient of $-0.5 ; P=0.05)$.

\section{Seasonal Variation}

Nonlinear multidimensional scaling (MDS) in 3 dimensions was conducted on melting properties to describe variation between sites across seasons for the $2 \mathrm{yr}$. The MDS analysis showed that each of the areas had their own characteristics. The results for SFC at $5^{\circ} \mathrm{C}$ are shown in Figure 5, together with the groupings that could be made. The stress in the MDS was 0.060; values below 0.1 are considered to provide good ordination and values below 0.05 indicate excellent ordination (Cox and Cox, 1992; Clarke, 1993).

Grouped based on similarity in range and median melting properties from the box plots (Figure $2 \mathrm{~A}$ to $\mathrm{C}$ ) and their seasonal variation in the MDS were group A with the New South Wales (site 1), Queensland (sites 2 and 3), and South Australia (site 4) sites; group B with the western Victoria sites (8, 9, and 10); group $\mathrm{C}$ with the northern Victoria sites (sites 11, 12, and 13); group D with Tasmanian (sites 5, 6, and 7) and eastern Victoria (sites 14, 15, and 17) sites; and group E with the Western Australia sites (18, 19, and 20). The preliminary MDS, which included site 16, yielded patterns indicating that this site was clearly separated from other sites in the graph of the first 2 dimensions. This confirmed site 16 as an atypical site for the region, as indicated by the box plots. Therefore, site 16 was not included in any of the regional groupings, as discussed earlier.

Results of the MDS of SFC at $20^{\circ} \mathrm{C}$ and of DP were broadly similar, with stresses of 0.076 and 0.067 , respectively (MDS graph results not shown). At $20^{\circ} \mathrm{C}$, the 5 groups were clearly discernible albeit with the 3 sites in the WA group being much less scattered than at $5^{\circ} \mathrm{C}$ and site 4 clearly separated from sites 1 to 3 in dimension 3. For DP, sites 3 and 20 were well away from the other sites in their group in all dimensions, site 11 was clearly separated from sites 12 and 13 in dimensions 2 and 3 , but the remaining sites remained in their groupings.

The monthly melting properties for the grouped sites are shown in Figure 6A to C. No distinct seasonal variation was shown by group $\mathrm{A}$ for $\mathrm{SFC}$ at $5^{\circ} \mathrm{C}$ and $20^{\circ} \mathrm{C}$ and 
only a relatively small seasonal pattern was observed for DP, with a low point around August. Sites 1 to 3 used irrigation all year and had a relatively stable yearround milk supply, but site 4 did not; no irrigation was used on site 4 and it had a very seasonal milk supply. Most pastures in site 4 were reclaimed swamp so they did not need irrigation to give active growing pasture year round, and the supplement feeds were reported to be the same for the whole survey period. Walker et al. (2013) reported that $\mathrm{SFC}$ at $10^{\circ} \mathrm{C}$ increased by about $0.2 \%$ for every kilogram of DM concentrate fed/cow per day. Most likely, the supplementary feeding regimens
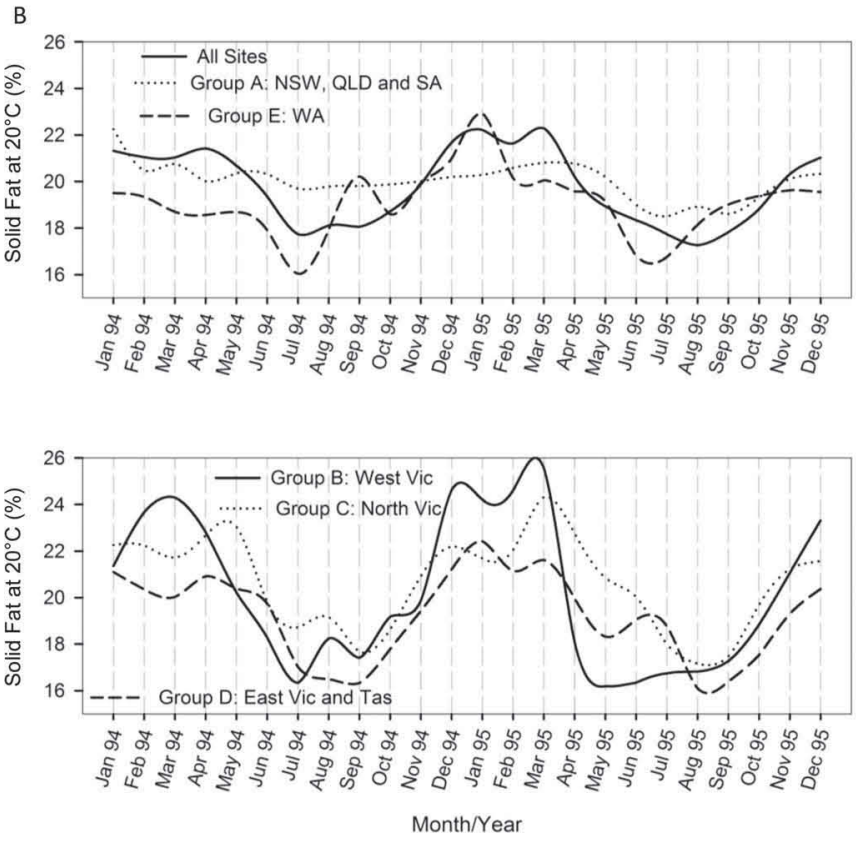

C
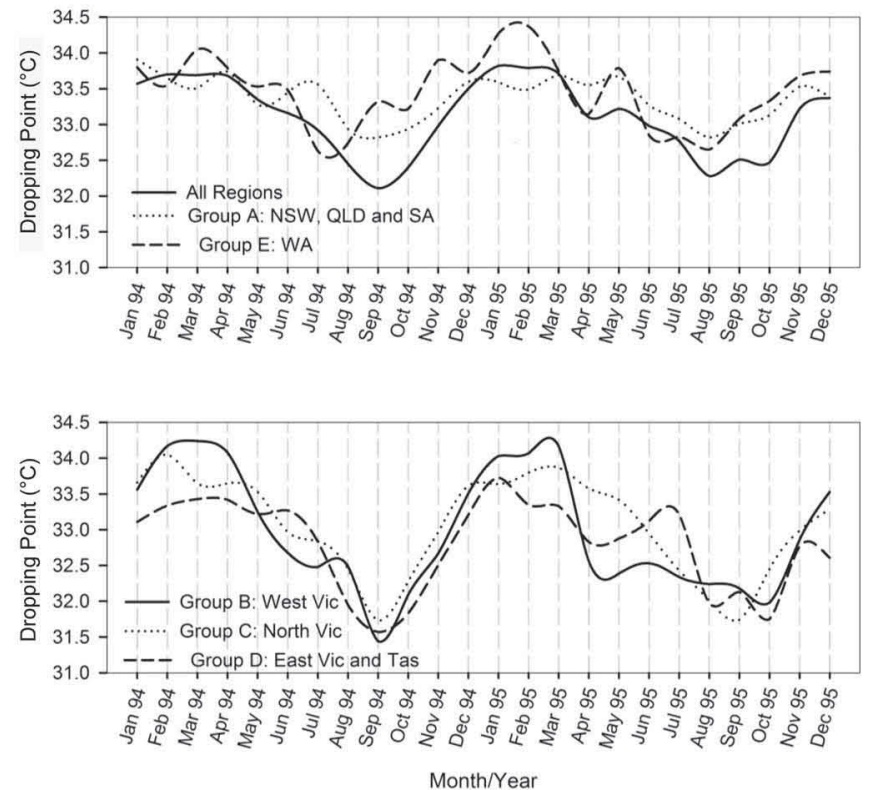

Figure 6. Solid fat at $5{ }^{\circ} \mathrm{C}$ (panel A), solid fat at $20^{\circ} \mathrm{C}$ (panel B), and dropping points $\left({ }^{\circ} \mathrm{C}\right.$; panel C) over 2 yr of milk fats from all Australian regions combined (excluding site 16) and of sites grouped in 5 regions (A to E). Differences between the curves are highly significant; SEM at each month (for panels $\mathrm{A}, \mathrm{B}$, and $\mathrm{C}$, respectively) are as follows: all regions $=0.10,0.08$, and 0.04 ; group $\mathrm{A}=0.16,0.14$, and 0.07 ; group $\mathrm{B}=$ $0.20,0.18$, and 0.09 ; group $\mathrm{C}=0.21,0.21$, and 0.10; group $\mathrm{D}=0.20,0.13$, and 0.07 ; and group $\mathrm{E}=0.30,0.22$, and 0.14 . NSW $=$ New South Wales; QLD = Queensland; SA = South Australia; WA = Western Australia; West Vic $=$ western Victoria; North Vic $=$ northern Victoria; East Vic $=$ eastern Victoria; Tas $=$ Tasmania 
helped to avoid the lows in SFC for site 4, as was found for all other seasonal production sites, so that it could be grouped with sites that had constant milk volume productions. The Western Australia sites (group E) showed some seasonal variation with a clear low SFC around July and more stable higher values throughout the year. All sites with no or small seasonal variation were also the only sites that reported kikuyu grass as part of the pasture at least part of the year; that is, sites of groups A and E (Table 1). From the available data, it is not possible to determine if kikuyu grass has some specific nutritional qualities affecting milk fat properties or is merely an indicator for general climate and growing conditions. Fulkerson et al. (2007) showed that grasses had a much higher hemicellulose content than legumes and kikuyu higher than other grasses. In an extensive review, Walker et al. (2004) concluded that high starch feed is associated with higher concentrations of saturated fatty acids, whereas a pasture diet would result in higher unsaturated fatty acids in the milk fat. This would most likely result in higher and lower solid fat contents, respectively, as shown by Couvreur et al. (2006), who found that the proportion of fresh grass to corn silage significantly affected fatty acid composition and butter hardness. Here they showed butter from cows fed a 30\% fresh grass diet exhibited maximum hardness compared with the softest butter coming from cows on a 100\% fresh grass diet. In our results, the seasonal variation in SFC and DP of sites in Victoria and Tasmania (groups B, C, and D) was mainly manifested through seasonal lows in winter and spring, when most fresh grass is available within those regions. Site 19 of group E (results not shown separately) had the least seasonal variation of the other sites in the group, and was the only site with seasonal irrigation in the low rainfall months and active pasture growth all year (Tables 1 and 2). The DP in Western Australia (group E) moved largely in parallel with SFC at $20^{\circ} \mathrm{C}$, except that the highs and lows lagged by about a month during 1995. Compared with the "national average" of all sites, the SFC at $5^{\circ} \mathrm{C}$ of group $\mathrm{E}$ tended to be lower, whereas the DP tended to be higher than that of all sites combined. This may provide some useful functionality, such as better spreadability for butter at refrigerated temperatures and, at the same time, having good resistance against melting and usability at elevated temperatures (e.g., for pastry sheeting).

In Victoria and Tasmania, groups $\mathrm{B}, \mathrm{C}$, and $\mathrm{D}$ showed strong seasonal variation across all melting properties. The SFC of group B (western Victoria) varied the most, and that of group $\mathrm{C}$ (northern Victoria), particularly at $5^{\circ} \mathrm{C}$, varied the least of these 3 groups, whereas DP showed a similar magnitude of variation for all 3 groups. The seasonal variations in SFC of group B (western Victoria) and group D (eastern Victoria and Tasmania) were very similar, except that the lows of group D occurred about 2 to 3 mo later in both years (approximately August vs. June). Regional differences were also noted by Knightbridge and Black (1978), who observed differences in the length of time for which SFC was at its lowest. Sites 11 and 12 in northern Victoria (group C) used irrigation all year, so less seasonal variation in melting properties might have been expected than was observed. It was noted that, in spite of irrigation, pasture availability was in short supply for about 6 mo of the year, unlike most sites in group A and site 19 in group E.

High values for SFC and DP were obtained at the end of spring and summer months. However, there appeared to be a shift in onset and decline of the curves, with high values of $\mathrm{SFC}$ at $5^{\circ} \mathrm{C}(\sim$ November 1994) being reached about a month before high values of SFC at $20^{\circ} \mathrm{C}(\sim$ December 1994$)$ followed by high values of DP a month later ( January 1995). Although less pronounced, the same observations could be made for the curves of all sites combined, which were heavily influenced by the results of the Victorian and Tasmanian sites. The values at the peak for group B are higher than those of group $\mathrm{C}$ and $\mathrm{D}$; however, the peaks of groups C and D are broader and the high SFC and DP are maintained longer into autumn or even into June, the beginning of winter, for group C.

From a study in northern Victoria, it was concluded that stage of lactation was the most significant factor affecting SFC (\%) in milk fat, with the amount of feed concentrate being a small contributing factor and other farm management factors and nutrition not having an influence (Walker et al., 2013). In our study, the $\mathrm{SFC}$ at $10^{\circ} \mathrm{C}$ was found to be more than $5 \%$ higher in early lactation than in mid to late lactation (data not shown). Therefore, from group A, the relative seasonal stability in SFC of sites 1 to 3 may be understandable. However, site 4 in our survey had strong seasonal milk production, with minimum flow being $17 \%$ of the maximum (Table 1); therefore, a strong seasonal calving profile and considerable seasonal variation in melting properties could be expected. If variation in $\mathrm{SFC}$ is mainly due to stage of lactation, then the same seasonal variation as observed for groups B, C, and D (sites 5 to 17, see Table 1) is to be expected. However, the variation in group $\mathrm{C}$, the same northern Victorian area as studied by Walker et al. (2013), showed much less seasonal variation than the other 2 groups (Figure $6 \mathrm{~A}$ ), whereas the seasonal production variation of site 12 (minimum flow $18 \%$ of the maximum) in northern Victoria in group $\mathrm{C}$ was much the same as that of sites 8,9 , and 10 in group B (17\%; Table 1). Therefore, it would appear that the degree of seasonal variation is 
affected considerably by feed, particularly in winter and early spring, when the milk fat in groups B and D has much less solid fat than that in group C. The "bumps" in SFC and DP, such as for group D in June-July 1995 (see Figure $6 \mathrm{~A}, \mathrm{~B}$, and $\mathrm{C}$ ), are likely to be caused by local feed quality and availability. There may also be an effect from different breeds; although the data sets are not complete and no region had single breeds (Table 1 ), the northern Victoria group C had more of the Jersey breed and fewer Friesians compared with the other 2 Victorian regions. MacGibbon (1996) noted that, at $10^{\circ} \mathrm{C}$, milk fat from Friesian herds had a lower SFC than that of Jersey herds, which is broadly consistent with our results for $\mathrm{SFC}$ at $5^{\circ} \mathrm{C}$ for the western and eastern Victorian regions compared with northern Victoria (Figure 6A). In addition, the Western Australia sites with the highest proportion of Friesians (96-98\%, Table 1) showed a relatively low $\mathrm{SFC}$ at $5^{\circ} \mathrm{C}$ compared with all other regions (group E; Figure 2D and 6A). The degree of variation in DP of group $\mathrm{C}$ was similar to that of groups B and D, and may, therefore, be attributed mainly to stage of lactation and less to nutrition, breed, or other farming practices.

From these results, no single factor stood out as determining the seasonal variation or lack thereof in milk fat melting properties. The milk from regions with no or small variation is mostly used in liquid milk products. Milk fat melting properties are unlikely to have a significant effect for these consumer products. The regions with the largest variations were in Victoria and Tasmania, which produce about $75 \%$ of Australia's milk, and which is mostly processed into cheese, milk powders, butter, and AMF for domestic and international markets (Dairy Industry in Focus, 2015). Milk fat melting properties are important in many applications and for users of butter, AMF, and whole milk powder. The variability in these regions highlights both the difficulty of producing consistent product and the opportunity to produce differential products for particular applications and markets. Milk fat dry fractionation is used on a large scale in many countries, although not in Australia, to make more functional milk fat-based products, such as spreadable butters and pastry butters (Kaylegian et al., 1993). Our analysis shows that some of the benefits of differentiated milk fat melting properties can be achieved by purposeful sourcing of milk. For instance, milk fat that is softer under refrigerated conditions (i.e., $5^{\circ} \mathrm{C}$ ) could be sourced from regions B and D between June and October. On the other hand, milk fat that is more solid at ambient temperature (i.e., $20^{\circ} \mathrm{C}$ ) could be sourced from these same regions from November to March, or from the region of group $\mathrm{C}$ between November and April. As such, it is possible to select desirable melting properties for certain products or markets for long periods of the year by staggered sourcing of produce or ingredients from different regions. This approach would be feasible for companies who have facilities in several regions in the same or different states. However, it is necessary and prudent to monitor milk properties during the season, as every year can be different in timing and magnitudes of peaks and troughs in melting properties (Figure 6A, B, and C). By doing this, the milk supply could be tailored to particular markets and applications. Functional properties affected by melting properties include the consistency and spreadability of butter associated with softer milk fat at ambient temperatures (Norris et al., 1973); the desired resistance to melting and plasticity of butter and AMF required for pastry production associated with a higher SFC (Deffense, 1993; Kaylegian and Lindsay, 1995); the whipability of cream, where a critical level of solid fat is required to promote coalescence (Darling, 1982); the suitability for blending of cream, butter, and AMF with other oils and fats for spreads; best use and conditions for further processing, such as fractionation for desirable fractions (Timms, 1980); and consistent performance in chocolate production, such as resistance to fat bloom and release from the mold (Lohman and Hartel, 1994; Dimick et al., 1996). Changes in farming practices over the last 20 yr may have reduced seasonal variations in milk fat properties with associated opportunities and problems in some regions. It is worth noting that the physical characteristics governing melting properties, including SFC and DP, are a function of the milk fat triglyceride fatty acid composition (Norris et al., 1973; Kaylegian and Lindsay, 1995) and will be the focus of a subsequent paper.

\section{CONCLUSIONS}

Differences in melting properties of milk fat from 19 bulk milk production sites across Australia were considerable and showed a clear seasonal pattern for the Victorian and Tasmanian sites, a moderate seasonal pattern for the Western Australia sites, and very little or no pattern for the New South Wales, Queensland, and South Australia sites that participated in the survey. In general, SFC at low temperatures and DP, which is a good measure of the melting properties at elevated temperatures, were highly correlated. Nevertheless, the time points for peaks and lows did not correlate and DP tended to lag by up to several months. For the site in New South Wales and one site in Western Australia, we detected no correlation between SFC at low temperatures and high temperatures or DP. Seasonally, the Western Australia sites showed lower SFC at low temperatures and higher DP than the national average. 
No single factor stood out as determining variation in melting properties. Sites with good availability, more active pastures with no senescence, and constant supplementary feed practices year round showed the least variation. To provide the most consistent functionality, it is recommended to select seasonal supplies from different regions for specific applications and products, which is best done in close collaboration with end users. Regular testing is also recommended because melting properties and timing of seasonal variation may differ from year to year.

\section{ACKNOWLEDGMENTS}

Gratefully acknowledged are Dairy Australia, Melbourne, Australia and the Department of Environment and Primary Industries Victoria, Melbourne, Australia for their financial support. Also we gratefully acknowledge all project team members, including Josie Accardi, Mark Alexander, Anne Birkett, Gail DiGregorio, Stephen Dungey, Fiona Leach, Margaret Papalois, Lynne Thomas, Michelle Rowney and Yolande Yep of the former Australian Food Industry Science Centre, Werribee (now part of CSIRO), for their contribution to the original survey project work, and Kym Butler and John Reynolds of the Department of Environment and Primary Industries Victoria for their contributions to the experimental design of the survey. Furthermore, the diligent collection and provision of samples and additional data of the factory and field staff of the following companies and their predecessors (with current or historic production sites): Murray Goulburn Co-operative Ltd (Koroit, Rochester, Cobram, Kiewa, Maffra, Leongatha); Lions Pty Ltd. (Gloucester, Margaret River, Harvey, Bentley and Simpson); Fonterra Australia (Drouin, Devonport, Legerwood, Wynyard); Parmalat Australia (Nambour and Monto); Department of Environment and Primary Industries Victoria (Ellinbank); United Dairy Power (Murray Bridge) and Warrnambool Cheese and Butter (Allansford) were instrumental for the completion of this project. Alec Zwart of CSIRO Data61 for statistical advice and Doug Eddy of the Dairy Industry Association of Victoria, Melbourne for his support to mine and publish in detail the survey data.

\section{REFERENCES}

Auldist, M. J., B. J. Walsh, and N. A. Thomson. 1998. Seasonal and lactational influences on bovine milk composition in New Zealand. J. Dairy Res. 65:401-411.

Banks, W., J. L. Clapperton, and W. Steele. 1983. Dietary manipulation of the content and fatty acid composition of milk fat. Proc. Nutr. Soc. 42:399-406.

Barnicoat, C. R. 1944. The softening-point of fats. Analyst (Lond.) 69:176-178.
Bartlett, M. S. 1937. Properties of sufficiency and statistical tests. Proc. R. Soc. Lond. A Math. Phys. Sci. 160:268-282.

Bazmi, A., A. Duquenoy, and P. Relkin. 2007. Aeration of low fat dairy emulsions: Effects of saturated-unsaturated triglycerides. Int. Dairy J. 17:1021-1027.

Boode, K., C. Bisperink, and P. Walstra. 1991. Destabilization of O/W emulsions containing fat crystals by temperature cycling. Colloids Surf. 61:55-74.

Clarke, K. R. 1993. Non-parametric multivariate analyses of changes in community structure. Aust. J. Ecol. 18:117-143.

Couvreur, S., C. Hurtaud, C. Lopez, L. Delaby, and J.-L. Peyraud. 2006. The linear relationship between the proportion of fresh grass in the cow diet, milk fatty acid composition, and butter properties. J. Dairy Sci. 89:1956-1969.

Cox, G. A., and F. H. McDowall. 1948. 371. The properties of New Zealand butters and butterfats I. Iodine, Reichert and saponification values and softening points of monthly samples of butterfats from nine commercial factories over four years. J. Dairy Res. $15: 377-386$.

Cox, M. A. A., and T. F. Cox. 1992. Interpretation of stress in nonmetric multidimensional scaling. Statistica Applicata 4:611-618.

Cox, T. F., and M. A. A. Cox. 2010. Multidimensional Scaling. CRC Press, Boca Raton, FL.

Cullinane, N., D. Condon, D. Eason, J. A. Phelan, and J. F. Connolly. 1984. Influence of season and processing parameters on the physical properties of Irish butter. Irish J. Food Sci. Technol. XX:13-25.

Dairy Industry in Focus. 2015. Appendix 3, Milk Production. Australia. Dairy Australia Limited, Melbourne.

Darling, D. F. 1982. Recent advances in the destabilization of dairy emulsions. J. Dairy Res. 49:695-712.

Deffense, E. 1993. Milk fat fractionation today: A review. J. Am. Oil Chem. Soc. 70:1193-1201.

Deman, J. M., L. Deman, and B. Blackman. 1983. Melting-point determination of fat products. J. Am. Oil Chem. Soc. 60:91-94.

Digby, P. G. N., and R. A. Kempton. 1987. Multivariate Analysis of Ecological Communities. Chapman and Hall, London, UK.

Dimick, P. S., G. R. Ziegler, N. A. Full, and S. Yella Reddy. 1996. Formulation of milk chocolate using milkfat fractions. Aust. J. Dairy Technol. 51:123-126.

Dolby, R. M. 1949. 398. The properties of New Zealand butters and butterfats: II. The relation of hardness of New Zealand commercial butter to composition of the butterfat. J. Dairy Res. 16:336-347.

Fisher, R. A., and F. Yates. 1963. Statistical Tables for Biological, Medical and Agricultural Research. Oliver and Boyd, Edinburgh, UK.

Fulkerson, W. J., J. S. Neal, C. F. Clark, A. Horadagoda, K. S. Nandra, and I. Barchia. 2007. Nutritive value of forage species grown in the warm temperate climate of Australia for dairy cows: Grasses and legumes. Livest. Sci. 107:253-264.

GenStat. 2013. GenStat for Windows. Vol. 16th ed. VSN International Ltd., Hemel Hempstead, UK.

Gordon, A. D. 1999. Classification. 2nd ed. Chapman and Hall/CRC Press, London, UK.

Hauser, J., and N. Lane. 2013. Victorian dairy industry milk supply trends: Analysis of the drivers of farm profit. Australia. Dairy Australia Limited, Melbourne.

Hillbrick, G., and M. A. Augustin. 2002. Milkfat characteristics and functionality: Opportunities for improvement. Aust. J. Dairy Technol. 57:45-51.

Huppertz, T. 2010. Foaming properties of milk: A review of the influence of composition and processing. Int. J. Dairy Technol. 63:477488.

Johnson, H. D. 1965. Environmental temperature and lactation (with special reference to cattle). Int. J. Biometeorol. 9:103-116.

Kaisersberger, E. 1989. DSC investigations of the thermal characterization of edible fats and oils. Thermochim. Acta 151:83-90.

Kankare, V., and V. Antila. 1988. Melting characteristics of milk fat, milk fat fractions and fat mixtures. Meijeritieteellinen Aikakauskirja XLVI 1:25-35.

Kaylegian, K. E., R. W. Hartel, and R. C. Lindsay. 1993. Applications of modified milk fat in food products. J. Dairy Sci. 76:1782-1796. 
Kaylegian, K. E., and R. C. Lindsay. 1995. Handbook of Milkfat Fractionation Technology and Applications. AOAC Press, Champaign, IL.

Kefford, B., M. P. Christian, B. J. Sutherland, J. J. Mayes, and C. Grainger. 1995. Seasonal influences on Cheddar cheese manufacture: influence of diet quality and stage of lactation. J. Dairy Res. 62:529-537.

Knightbridge, J. P., and R. G. Black. 1978. The variation in firmness of Victorian butters. Aust. J. Dairy Technol. 33:14-18.

Lohman, M. H., and R. W. Hartel. 1994. Effect of milk fat fractions on fat bloom in dark chocolate. J. Am. Oil Chem. Soc. 71:267-276.

Lopez, C., C. Bourgaux, P. Lesieur, and M. Ollivon. 2007. Coupling of time-resolved synchrotron X-ray diffraction and DSC to elucidate the crystallisation properties and polymorphism of triglycerides in milk fat globules. Lait 87:459-480.

MacGibbon, A. K. H. 1996. Herd-to-herd variations in the properties of milkfat. Pages 224-227 in Proc. New Zealand Soc. Anim. Prod. New Zealand Society of Animal Prod. Publ. Accessed Feb. 1, 2016. http://www.nzsap.org/proceedings/1996/herd-herd-variationsproperties-milkfat.

MacGibbon, A. K. H., and W. D. McLennan. 1987. Hardness of New Zealand patted butter- Seasonal and regional variations. N.Z. J. Dairy Sci. Tech. 22:143-156.

McCarthy, O. J. 2006. Physical characterization of milk fat and milk fat-based products. Pages 725-778 in Advanced Dairy Chemistry Volume 2 Lipids. P. F. Fox and P. L. H. McSweeney, ed. Springer, New York, NY.

McClements, D. J., and M. J. W. Povey. 1987. Solid fat content determination using ultrasonic velocity measurements. Int. J. Food Sci. Technol. 22:491-499.

Meagher, L. P., S. E. Holroyd, D. Illingworth, F. van de Ven, and S. Lane. 2007. At-line near-infrared spectroscopy for prediction of the solid fat content of milk fat from New Zealand butter. J. Agric. Food Chem. 55:2791-2796.

Norris, G. E., I. K. Gray, and R. M. Dolby. 1973. Seasonal variations in the composition and thermal properties of New Zealand milk fat: II. Thermal properties of milk fat and their relation to composition. J. Dairy Res. 40:311-321.
Papalois, M., F. W. Leach, S. Dungey, Y. L. Yep, and C. Versteeg. 1996. Australian milkfat survey-Physical properties. Aust. J. Dairy Technol. 51:114-117.

Parodi, P. W. 1979. Relationship between trisaturated glyceride composition and the softening point of milk fat. J. Dairy Res. 46:633639.

Patterson, H. D., and R. Thompson. 1971. Recovery of inter-block information when block sizes are unequal. Biometrika 58:545-554.

Precht, D. 1994. Jahreszeitliche Variation von Butterfettkennzahlen unterschiedlicher Milcheinzugsgebiete. Kieler Milchwirtsch. Forschungs. 46:65-79.

Robinson, D. L. 1987. Estimation and use of variance components. Statistician 36:3-14.

Shen, Z., A. Birkett, M. A. Augustin, S. Dungey, and C. Versteeg. 2001. Melting behavior of blends of milk fat with hydrogenated coconut and cottonseed oils. J. Am. Oil Chem. Soc. 78:387-394.

Smith, A. K., H. D. Goff, and Y. Kakuda. 2000. Microstructure and rheological properties of whipped cream as affected by heat treatment and addition of stabilizer. Int. Dairy J. 10:295-301.

Thomas, L., and M. Rowney. 1996. Australian milkfat survey-Fatty acid composition. Aust. J. Dairy Technol. 51:112-114.

Timms, R. 1980. The phase behaviour and polymorphism of milk fat, milk fat fractions and fully hardened milk fat. Aust. J. Dairy Technol. 35:47-53.

Timms, R. E. 1978. Automatic determination of the softening point of milk fat, milk fat fractions and butter. Aust. J. Dairy Technol. 33:143-147.

Walker, G. P., F. R. Dunshea, and P. T. Doyle. 2004. Effects of nutrition and management on the production and composition of milk fat and protein: A review. Crop Pasture Sci. 55:1009-1028.

Walker, G. P., C. Wijesundera, F. R. Dunshea, and P. T. Doyle. 2013. Seasonal and stage of lactation effects on milk fat composition in northern Victoria. Anim. Prod. Sci. 53:560-572.

Walker, R. C., and W. A. Bosin. 1971. Comparison of SFI, DSC and NMR methods for determining solid-liquid ratios in fats. J. Am. Oil Chem. Soc. 48:50-53. 